\title{
Multilevel models in international business research
}

\author{
Mark F Peterson ${ }^{1,2}$, \\ Jean-Luc Arregle ${ }^{3}$ and \\ Xavier Martin 4
}

${ }^{1}$ Florida Atlantic University, Boca Raton, USA;

${ }^{2}$ Maastricht University, The Netherlands;

${ }^{3}$ EM Lyon Business School, Ecully, France;

${ }^{4}$ School of Economics and Management, Center for Innovation Research and Center for Research in Economics and Business Administration, Tilburg University, The Netherlands

Correspondence:

J-L Arregle,

EM Lyon Business School, 23 avenue Guy de Collongue, 69134 Ecully Cedex, France. Tel: + 334783370 25;

Fax: + 334783379 27;

email: arregle@em-lyon.com
Received: 29 August 2011

Revised: 14 November 2011

Accepted: 21 November 2011

\begin{abstract}
Multiple-level (or mixed linear) modeling (MLM) can simultaneously test hypotheses at several levels of analysis (usually two or three), or control for confounding effects at one level while testing hypotheses at others. Advances in multi-level modeling allow increased precision in quantitative international business (IB) research, and open up new methodological and conceptual possibilities. However, they create new challenges, and they are still not frequently used in IB research. In this editorial we outline some key methodological issues for the uses of MLM in IB, including criteria, sample size, and measure equivalence issues. We then examine promising directions for future multilevel IB research considering comparative opportunities at nation, multiple-nation cluster, and within-nation region levels, including large multilevel databases. We also consider its promise for MNE research about semi-globalization, interorganizational effects across nations, clusters within nations, and teams and subsidiaries within MNEs. Journal of International Business Studies (2012) 43, 45I-457. doi: $10.1057 / j i b s .2011 .59$
\end{abstract}

Keywords: multilevel models; mixed linear methods; levels of analysis

\section{INTRODUCTION}

Research published in the Journal of International Business Studies often links institutional or cultural characteristics of nations to features of businesses and business people that are nested within nations. Other research analyzes subsidiaries nested within multinational enterprises and economic regions. Previously, such work has matched samples on selected characteristics such as organizational (Hofstede, 1980/2001) or industry context (Fischer, Vauclair, Fontaine, \& Schwartz, 2010; House, Hanges, Javidan, Dorfman, Gupta, \& GLOBE Associates, 2004) in a way that reduced internal validity problems, but which required external validation for application in other contexts.

One option for dealing with that problem was to aggregate variables at the lower level (Level 1) to a higher level (Level 2). Alternatively, Level 2 data were often disaggregated to Level 1. Both approaches have limitations. Aggregation removes Level 1 variance and eliminates the opportunity to control for Level 1 confounding variables. Hence it creates the risk of ecological fallacy, that is, "the assumption that relationships between variables at the aggregate level imply the same relationships at the individual level" (Jargowsky, 2005: 715). Disaggregation produces biased statistics by 
treating Level 2 values that are assigned to Level 1 observations as independent (Arregle, Hebert, \& Beamish, 2006).

By using multi-level modeling (MLM), however, researchers studying higher-level constructs can effectively control for theoretically extraneous individual-level variables (Cullen, Parboteeah, \& Hoegl, 2004), and researchers studying lower-level constructs can treat Level 2 contingencies as continuous rather than categorical variables (Smith, Peterson, Thomason, \& the Event Meaning Management Research Group, 2011). MLM thus allows IB scholars to accurately model context and lowerlevel effects.

This editorial is not intended to resolve all MLM controversies in IB by editorial fiat, but explains some critical considerations and literatures that are often overlooked in MLM research. We first introduce statistical tools, and discuss issues in using them. We then consider directions for international comparative research and MNE research.

MULTILEVEL ANALYTICAL TOOLS AND ISSUES The basics of MLM methods for analyzing nested data are well known (e.g., Hofmann, 1997), but criteria for deciding when to use them remain controversial. Recent advances in analysis methods create unrealized potential for IB research.

\section{MLM Basics}

Although MLM models can be used with more than two levels of nesting, two-level models are the most common. They take the basic form

Level 1:

$$
Y_{i j}=\beta_{0 j}+\beta_{1 j} X_{i j}+r_{i j}
$$

Level 2:

$$
\beta_{0 j}=\gamma_{00}+\gamma_{01} W_{j}+u_{0 j}
$$

and

$$
\beta_{1 j}=\gamma_{10}+\gamma_{11} W_{j}+u_{1 j}
$$

where $i$ is a Level 1 observation, $j$ is a Level 2 observation, $X$ is a Level 1 predictor, and $W$ is a Level 2 predictor.

In "intercepts and slopes as outcomes" models, $\beta_{0 j}$ (an intercept) and $\beta_{1 j}$ (a slope) are explained by variables measured at the higher level (Level 2 ). The intercepts part of the model predicts differences in the average level of a dependent variable at Level 1 from some Level 2 independent variable.
The slopes part of the model predicts the relationship between two Level 1 variables from some Level 2 variable. In simple nested models, each Level 1 observation belongs only to one Level 2 group. By contrast, in cross-nested (or cross-classified) MLM a Level 1 observation can be nested in two Level 2 groups. Longitudinal studies can nest separate occasions of events (as Level 1 observations) within characteristics of situations that are modeled as stable (Level 2) characteristics (Martin, Swaminathan, \& Tihanyi, 2007).

\section{Criteria for Using Mixed Linear Models}

The criteria for deciding whether to use MLM are generally well known, but the specific cut-off points for an appropriate application are more controversial. Consider three cases.

First, when a research problem suggests that the means of variables measured at Level 1 can be predicted by a Level 2 variable, intraclass correlation coefficients (ICCs) or similar methods are used to determine that the Level 1 observations differ significantly between Level 2 groups (Bliese \& Hanges, 2004; Hanges \& Dickson, 2004). As a rule of thumb, Hox (2010) considers ICCs of 0.05, 0.10, and 0.15 as small, medium, and large, respectively, for organizational research.

Second, other research problems simply require that Level 2 effects be controlled. For example, a study might test for a consistent relationship between strategy and organizational effectiveness across a small number of nations, multiplenation regions, or time periods. When the purpose is to control for nesting rather than to test Level 2 hypotheses, and such small numbers of Level 2 groups limit the power to identify significant Level 2 effects, the criterion that one should first demonstrate significant Level 2 effects is relaxed.

Third, when the researcher is interested in differences in relationships between Level 1 variables depending on a Level 2 variable, then the ICC test to show mean differences in Level 1 variables among Level 2 groups is not relevant. Instead, researchers should test whether Level 1 slopes differ between Level 2 units before attempting to explain differences in slopes (Raudenbush, Bryk, Cheong, Congdon, \& du Toit, 2004). IB researchers should heed the difference in the utility of ICCs and similar coefficients for evaluating the appropriateness of MLM to handle these three very different research problems. 


\section{Level 1 and Level 2 Sample Sizes}

Sample-size problems arise in multilevel international research because of the limited number of nations in the world, data quality and accessibility problems for many nations, interest in studying multiple-nation groupings, availability of data from few time periods, or the small number of members in teams or subsidiaries in MNEs. Sample-size criteria are based on numbers of predictors at each level, and on whether fixed effects or random effects models are being studied.

In MLM, fixed effects describe group-specific features assumed to affect the dependent variable, whereas random effects assume that the group is drawn randomly from a larger population. Fixedeffects models, which can thus be useful for researchers interested only in interpreting the specific Level 2 groups being studied, require fewer Level 2 groups than do random-effects models that seek generalization to populations represented by the Level 2 groups.

Kreft (1996) suggested 30 Level 2 groups and 30 Level 1 observations per group. Simulation studies indicate that the balance swings toward more than 30 groups and fewer than 30 observations per group for hypotheses about the effects of Level 2 variables (e.g., Maas \& Hox, 2005; Snijders $\&$ Bosker, 1993). For a two-level model, Hox (2010) recommends at least 20 observations for 50 groups to test cross-level interactions, and at least 10 observations for 100 groups to test random effects. He also presents detailed power analyses based on both sample sizes and anticipated effect sizes. Spybrook, Raudenbush, Congdon, and Martínez (2011) provide software for power analysis for specific MLM situations. ${ }^{1}$

MLM can also use unbalanced data with different numbers of observations per group. Bell, Ferron, and Kromrey (2008) even apply it when a small percentage of groups have only one or two observations. For research with few Level 2 groups, moderated regression or multi-group structural equation modeling that treats the groups as categories only may be more appropriate than MLM (Meuleman \& Billiet, 2009).

IB researchers should stay abreast of research about MLM sample sizes, since this literature is still evolving. They should also note that most simulation studies are based on simple models with only one Level 1 and one Level 2 predictor, so their results may yet understate the sample size demands for the more complex multivariate models of interest to IB scholars.
Measure Equivalence at Multiple Levels

MLM research relating higher level (e.g., Level 2) predictors to group means of Level 1 criteria should consider whether or not the variables represented by group means are comparable to their individual-level measurement structures. Factor structures can be compared at multiple levels of analysis (Hanges \& Dickson, 2004; Muthen, 1994), but scholars continue to debate whether factor equivalence across levels is always desirable (Fischer et al., 2010). For example, using measures of values at both national and individual levels requires that a researcher consider how parties at a lower level respond to their shared experiences with the values that characterize their societies (Peterson $\&$ Wood, 2008). Obviously, not all groups or individuals wholly accept their society's values. The frequent finding of more differentiated valuerelated factors at individual than at aggregate levels can either be an artifact of smaller samples and variance in aggregated data or have a substantive basis (Ostroff, 1993; Peterson, 2009). Scholars who argue that either Level 1 and Level 2 data structures should be similar, or that they should differ, need to provide both statistical and substantive explanations for their position.

\section{Recent Advances in Analysis Methods}

New methods and statistical software for MLM research regularly appear. MLM has become available for analyzing dichotomous, nominal, count, ordinal, and truncated dependent variables (Cuypers \& Martin, 2010). Methods for testing mediating effects are also available, although they are complex and sensitive (Zhang, Zyphur, \& Preacher, 2009).

In the next two sections, we consider specific directions for the fruitful use of MLM in IB: international comparative research and $\mathrm{MNE}$ research, respectively.

\section{INTERNATIONAL COMPARATIVE RESEARCH}

Multilevel datasets and analysis methods draw attention to controversies about concepts such as nations, multiple-nation groupings, and withinnation regions (Hitt, Beamish, Jackson, \& Mathieu, 2007; Peterson \& Soendergaard, 2011).

\section{Nations}

The concept of nation is surprisingly controversial (Smith, 2004). At one extreme, the nation is either a taken-for-granted construct, or is something that distinguishes what is legitimately IB research from 
what is not (Tung \& van Witteloostuijn, 2008). At the other extreme, nations are seen as being so ephemeral that they are inconsequential (Tsui, Nifadkar, \& Ou, 2007).

Addressing these extremes has encouraged scholars to think about nations in increasingly nuanced ways (Peterson \& Soendergaard, 2011; Tung, 2008). Studies testing Level 1 hypotheses that control for nesting of individuals or organizations within nations should use MLM when ICCs show significant nation differences in Level 1 variables. Studies using simple designs that have no interest in generalizing beyond the nations studied (e.g., nations of Latin America) can use fixed-effects statistics to test nation-level hypotheses that require relatively few Level 2 observations. Studies with multiple nation-level predictors, or which use random-effects statistics to make inferences to nations in general, need to pay special attention to power limitations (Hox, 2010).

Although MLM cannot solve the theoretical problem of the significance of nation-states, it is and should continue to be used by IB researchers to probe the utility of studying nation-states as compared with multiple-nation clusters and within-nation regions.

\section{Multiple-Nation Clusters}

IB scholars sometimes combine sets of nations. Cultural rationales for grouping nations can be based on functional similarities, ancient history, historical institutional spread, traditional occupations, modern institutional arrangements, economics, or economic change (Gupta \& Hanges, 2004; Inglehart \& Baker, 2000; Schwartz, 2004). Economic rationales for clustering have been proposed when nations are physically contiguous or economically integrated (Arregle, Beamish, \& Hebert, 2009; Rugman \& Verbeke, 2004). The cultural basis and the economic basis for clustering nations can overlap when economic ties have cultural implications (or the opposite). Proximity can promote cultural convergence through cross-border interaction and the development of international integrative mechanisms that promote cross-border business relationships.

Since applications of research about multiplenation clusters are typically to the specific clusters studied rather than to a larger population of clusters, fixed-effects models are often appropriate. The number of multiple-nation clusters is typically too limited to test hypotheses about them as the higher level in MLM (i.e., Level 2 in two-level models or Level 3 in three-level models). Nevertheless, theoretical considerations often suggest that nation clusters should be treated as controls or studied using other methods. Nation clusters could also be used at the intermediate level (e.g., Level 2 in a three-level model) in MLM with more than two levels, as long as the sample sizes at the different levels are sufficient.

\section{Within-Nation Regions}

The increasingly documented variability in cultural, institutional, and economic characteristics within nations suggests that IB researchers should consider studying within-nation regions (e.g., Chan, Makino, \& Isobe, 2010; Crone, 2005; Lenartowicz \& Roth, 2001). When something that is typically conceived as a nation characteristic also shows meaningful within-nation differences, considering regions as a level of analysis has the potential to overcome the Level 2 sample size problem that plagues MLM research in IB.

\section{Large-scale Datasets about Societies}

IB scholars should take advantage of the large international datasets about social, cultural, and economic characteristics that are now publicly available. For example, data at the individual, nation and sometimes the within-nation region levels are available for versions of the Schwartz Value Survey (Fischer et al., 2010), World Value Survey (Inglehart, Basañez, \& Moreno, 1998), European Social Survey (2011), and Global Entrepreneurship Monitor (2010), and from Eurostat. While promising, these databases have common limitations that are only partially compensated for by their large sample sizes. One is that items often use simple words and dichotomous response alternatives to accommodate respondents with limited education. Another is the frequent use of singleitem scales, making translation equivalence and response bias difficult to evaluate (Hult et al., 2008).

\section{RESEARCH ABOUT MNES}

Our discussion to this point has emphasized comparative projects where nation is one level of nesting. We also see several research directions for multilevel research about MNEs.

\section{From Globalization to Semi-Globalization}

A "global" perspective on MNEs that connects global headquarters with country-level subsidiaries dominates IB (Rugman \& Verbeke, 2004). However, a 
recent semi-globalization approach holds that incomplete cross-border integration generates neither global integration nor national market fragmentation (Ghemawat, 2003). Consequently, multi-nation regions affect MNEs' international strategy. Firms investing in particular regions recognize that some countries share economic and political interdependence, common cultural or ethnic heritages, or historically developed relations that can support firm-specific advantages (Rugman \& Verbeke, 2004). Such regions can be more culturally or institutionally meaningful than nations. When region-level sample sizes allow, IB researchers should use MLM to consider whether well-known relationships at the country or foreign direct investment (FDI) level also appear at the region level. Scholars should also consider such unique effects of a region as, for instance, whether region-level experience complements or substitutes for country-level experience in determining entry mode.

\section{Interorganizational Effects and Clusters within Countries}

Recognizing that FDI decisions are affected by the actions of other firms, IB scholars have studied the relative effects of buyers and rivals (Martin, Swaminathan, \& Mitchell, 1998), timing as well as count effects (Martin et al., 1998), and institutional forms such as business groups (Belderbos \& Sleuwaegen, 1996) - all potentially fruitful areas for MLM (Martin et al., 2007). Recognizing the pros and cons for each firm in agglomerating with rival or complementary firms (Shaver \& Flyer, 2001), researchers should continue to examine clusters in foreign entry (Martin, Salomon, \& Wu, 2010). MLM should also be used to connect such cluster effects with differences in economic and cultural attractiveness of regions within nations.

\section{Teams and Subsidiaries within the MNE}

Much research on intercultural teams in MNEs is conceptual, experimental, or ethnographic (Leung $\&$ Peterson, 2010). Large-scale surveys can contribute as well. Thus Leung and Peterson (2010) propose team characteristics (e.g., diversity of knowledge and perspectives) and outcomes at Level 1, vs communication technology (e.g., amount of physical presence) at Level 2. Intercultural negotiation research (Brett \& Crotty, 2008) compares the influence of the personal values of team members on various negotiation processes and outcomes (potentially Level 1) vs national culture characteristics of the negotiating teams (potentially Level 2). Research on MNEs has also focused on the effects of MNE-subsidiary relationships, subsidiary environments, and networks across subsidiaries on various organizational outcomes. MLM not only perfectly fits the multilevel structure of these research questions; it also allows a better and more elaborated modeling, opening up new theoretical perspectives for quantitative studies on this topic. Accordingly, MLM should be used to study how higher-level nation or MNE variables, and lower-level subsidiary or team variables, and their interactions, explain lower-level decisions and outcomes.

\section{CONCLUSION}

Studies using MLM methods occasionally appear in JIBS, but MLM continues to have unrealized potential for addressing a broad range of international comparative and MNE research topics. Methodologically, we have pointed out that researchers using MLM must first thoroughly understand the nature of the multilevel nesting and relationships in their data and hypotheses, and the corresponding diagnosis and sample size requirements. In our collective editing experience, we frequently find submissions in which the level of analysis of the theory, measures, or analysis techniques do not match. We also find MLM submissions based on datasets that lack the sample sizes for the sorts of hypotheses being tested, and we find regression-based submissions using solely either disaggregated or aggregated analyses that would be better conducted using MLM. Equally importantly, MLM is attuned to the increasing conceptual sophistication of IB research. The combination of MLM with advances in theory about the significance of nations, as well as about levels such as clusters of nations, within-nation regions, and MNE groups and subunits, suggests that MLM should and will have an increasing role in IB research well into the future, whenever conditions for its use are met.

\section{ACKNOWLEDGEMENTS}

The authors thank Shige Makino and Anand Swaminathan for contributions to an earlier version of this editorial; and Paul Bliese, Fons van de Vijver, the JIBS Editors and Area Editors, and three anonymous reviewers for their useful comments.

\section{NOTES}

${ }^{1}$ Beside this Optimal Design software, other packages to determine the appropriate sample size based on power estimates in specific cases of MLM include PinT (http://www.stats.ox.ac.uk/ snijders) and RMASS (http://www.healthstats.org/rmass/). 


\section{REFERENCES}

Arregle, J. L., Hebert, L., \& Beamish, P. W. 2006. Mode of international entry: The advantages of multilevel methods. Management International Review, 46(5): 557-618.

Arregle, J. L., Beamish, P. W., \& Hebert, L. 2009. The regional dimension of MNEs' foreign subsidiary localization. Journal of International Business Studies, 40(1): 86-107.

Belderbos, R., \& Sleuwaegen, L. 1996. Japanese firms and the decision to invest abroad: Business groups and regional core networks. Review of Economics and Statistics, 78(2): 214-220.

Bell, B. A., Ferron, J. M., \& Kromrey, J. D. 2008. Cluster size in multilevel models: The impact of sparse data structures on point and interval estimates in two-level models. Proceedings of the Joint Statistical Meetings, Survey Research Methods Section, 1122-1129. Alexandria, VA: American Statistical Association.

Bliese, P. D., \& Hanges, P. J. 2004. Being both too liberal and too conservative: The perils of treating grouped data as though they were independent. Organizational Research Methods, 7(4): 400-417.

Brett, J. M., \& Crotty, S. 2008. Culture and negotiation. In P.B. Smith, M.F. Peterson, \& D.C. Thomas (Eds), Handbook of cross cultural management research: 269-284. Beverly Hills, CA: Sage Press.

Chan, C. M., Makino, S., \& Isobe, T. 2010. Does subnational region matter? Foreign affiliate performance in the United States and China. Strategic Management Journal, 31(11): 1226-1243.

Crone, T. M. 2005. An alternative definition of economic regions in the United States based on similarities in state business cycles. Review of Economics and Statistics, 87(4): 617-626.

Cullen, J. B., Parboteeah, K. P., \& Hoegl, M. 2004. Crossnational differences in managers' willingness to justify ethically suspect behaviors: A test of institutional anomie theory. Academy of Management Journal, 47(3): 411-421.

Cuypers, I. R. P., \& Martin, X. 2010. What makes and what does not make a real option? A study of equity shares in international joint ventures. Journal of International Business Studies, 41(1): 47-69.

European Social Survey. 2011. www.europeansocialsurvey.org.

Fischer, R., Vauclair, M., Fontaine, J. R. J., \& Schwartz, S. H. 2010. Are individual-level and country-level value structures different? Testing Hofstede's legacy with the Schwartz Value Survey. Journal of Cross-Cultural Psychology, 41(2): 135-151.

Ghemawat, P. 2003. Semiglobalization and international business strategy. Journal of International Business Studies, 34(2): 138-152.

Global Entrepreneurship Monitor. 2010. www.gemconsortium .org.

Gupta, V., \& Hanges, P. J. 2004. Regional and climate clustering of societal cultures. In R. J. House, P. J. Hanges, M. Javidan, P.W. Dorfman, \& V. Gupta (Eds), Culture, leadership, and organizations: The GLOBE study of 62 societies: 178-218. Thousand Oaks, CA: Sage.

Hanges, P. J., \& Dickson, M. W. 2004. The development and validation of the GLOBE culture and leadership scales. In R. J. House, P. J. Hanges, M. Javidan, P. W. Dorfman, \& V. Gupta (Eds), Culture, leadership, and organizations: The GLOBE study of 62 societies: 122-151. Thousand Oaks, CA: Sage.

Hitt, M. A., Beamish, P. W., Jackson, S. E., \& Mathieu, J. E. 2007. Building theoretical and empirical bridges across levels: Multilevel research in management. Academy of Management Journal, 50(6): 1385-1399.

Hofmann, D. A. 1997. An overview of the logic and rationale of hierarchical linear models. Journal of Management, 23(6): 723-744.

Hofstede, G. 1980/2001. Culture's consequences: Comparing values, behaviors, institutions, and organizations across nations. Thousand Oaks, CA: Sage Publications.

House, R. J., Hanges, P. J., Javidan, M., Dorfman, P. W., \& Gupta, V. \& GLOBE Associates 2004. Culture, leadership, and organizations: The GLOBE study of 62 societies. Thousand Oaks, CA: Sage.
Hox, J. J. 2010. Multilevel analysis: Techniques and applications (2nd edn): New York: Routledge.

Hult, G. T. M., Ketchen, D. J., Griffith, D. A., Finnegan, C. A Gonzalez-Padron, T., Hamancioglu, N., Huang, Y., Talay, M. B., \& Cavusgil, S. T. 2008. Data equivalence in cross-cultural international business research: Assessment and guidelines. Journal of International Business Studies, 39(6): 1027-1044.

Inglehart, R., \& Baker, W. E. 2000. Modernization, cultural change, and the persistence of traditional values. American Sociological Review, 65(1): 19-51.

Inglehart, R., Basañez, M., \& Moreno, A. 1998. Human values and beliefs: A cross-cultural sourcebook. Ann Arbor: University of Michigan Press.

Jargowsky, P. A. 2005. Ecological fallacy. In K. Kempf-Leonard (Ed), Encyclopedia of social measurement: 715-722. San Diego, CA: Elsevier.

Kreft, I. G. G. 1996. Are multilevel techniques necessary? An overview, including simulation studies. Los Angeles, CA: California State University at Los Angeles.

Lenartowicz, T., \& Roth, K. 2001. Does subculture within a country matter? A cross-cultural study of motivational domains and business performance in Brazil. Journal of International Business Studies, 32(2): 305-325.

Leung, K., \& Peterson, M. F. 2010. Globally distributed workforce: Social and international issues. In S. Zedeck, H. Aguinis, W. F. Casio, M. J. Gelfand, K. Leung, S. K. Parker, \& 1. Zhou (Eds), Handbook of industrial-organizational psychology: 771-805. Washington, DC: APA.

Maas, C. J. M., \& Hox, J. J. 2005. Sufficient sample sizes for multilevel modeling. Methodology, 1(3): 86-92.

Martin, X., Salomon, R. M., \& Wu, Z. 2010. The institutional determinants of agglomeration: A study in the global semiconductor industry. Industrial and Corporate Change, 19(6): 1769-1800.

Martin, X., Swaminathan, A., \& Mitchell, W. 1998. Organizational evolution in the interorganizational environment: Incentives and constraints on international expansion strategy. Administrative Science Quarterly, 43(3): 566-601.

Martin, X., Swaminathan, A., \& Tihanyi, L. 2007. Modeling international expansion. In D.J. Ketchen \& D.D. Bergh (Eds), Research methodology in strategy and management, Vol. 4, 101-117. Amsterdam: Elsevier.

Meuleman, B., \& Billiet, J. 2009. A Monte Carlo sample size study: How many countries are needed for accurate multilevel SEM? Survey Research Methods, 3(1): 45-58.

Muthen, B. 1994. Multilevel covariance structure analysis. Sociological Methods and Research, 22(30): 376-398.

Ostroff, C. 1993. Comparing correlations based on individuallevel and aggregated data. Journal of Applied Psychology, 78(4): 569-582.

Peterson, M. F. 2009. Cross-cultural comparative studies and problems of coordinating international research teams. In D. A. Buchanan \& A. Bryman (Eds), Handbook of organizational research methods: 328-345. London: Sage.

Peterson, M. F., \& Soendergaard, M. 2011. Traditions and transitions in quantitative societal culture research in organization studies. Organization Studies, 32(11): 1539-1558.

Peterson, M. F., \& Wood, R. E. 2008. Cognitive structures and processes in cross cultural management. In P. B. Smith, M. F. Peterson, \& D.C. Thomas (Eds), Handbook of cross-cultural management research: 15-33. Thousand Oaks, CA: Sage.

Raudenbush, S. W., Bryk, A. S., Cheong, Y. F., Congdon, R., \& du Toit, M. 2004. HLM 6: Linear and nonlinear modeling. Lincolnwood, IL: Scientific Software International.

Rugman, A. M., \& Verbeke, A. 2004. A perspective on regional and global strategies of multinational enterprises. Journal of International Business Studies, 35(1): 3-18.

Schwartz, S. H. 2004. Mapping and interpreting cultural differences around the world. In H. Vinken, J. Soeters, \& 
P. Ester (Eds), Comparing cultures: Dimensions of culture in a comparative perspective: 43-73. Leiden: Brill.

Shaver, J. M., \& Flyer, F. 2001. Agglomeration economies, firm heterogeneity, and foreign direct investment in the United States. Strategic Management Journal, 21(12): 1175-1193.

Smith, P. B. 2004. Nations, cultures, and individuals: New perspectives and old dilemmas. Journal of Cross-Cultural Psychology, 35(1): 6-12.

Smith, P. B., Peterson, M. F., \& Thomason, S. P. \& the Event Meaning Management Research Group 2011. National culture as a moderator of the relationship between leaders' use of guidance sources and how well work events are handled. Journal of Cross Cultural Psychology, 42(6): 1103-1123.

Snijders, T. A. B., \& Bosker, R. J. 1993. Standard errors and sample sizes for two-level research. Journal of Educational and Behavioral Statistics, 18(3): 237-259.

Spybrook, J., Raudenbush, S. W., Congdon, R., \& Martínez, A. 2011. Optimal design for longitudinal and multilevel research: Documentation for the "Optimal Design" software. Available from http://www.wtgrantfoundation.org. or from http:// sitemaker.umich.edu/group-based.

Tsui, A. S., Nifadkar, S. S., \& Ou, A. Y. 2007. Cross-national, cross-cultural organizational behavior research: Advances, gaps, and recommendations. Journal of Management, 33(3): 426-478.

Tung, R. L. 2008. The cross-cultural research imperative: The need to balance cross-national and intra-national diversity. Journal of International Business Studies, 39(1): 41-46.

Tung, R. L., \& van Witteloostuijn, A. 2008. From the editors: What makes a study sufficiently international? Journal of International Business Studies, 39(1): 180-183.

Zhang, Z., Zyphur, M. J., \& Preacher, K. J. 2009. Testing multilevel mediation using hierarchical linear models: Problems and solutions. Organizational Research Methods, 12(4): 695-719.

\section{ABOUT THE AUTHORS}

Mark F. Peterson (PhD, Michigan) is Professor of International Management at Florida Atlantic University, and holds the Hofstede Chair in Cultural Diversity at Maastricht University. His principal interests are in culture and intercultural relations. He has authored over 100 articles and chapters for publications such as Administrative Science Quarterly,
Academy of Management Journal, Journal of International Business Studies, Journal of Organizational Behavior, Organization Science, the Annual Review of Psychology, and the Handbook of Industrial and Organizational Psychology. He recently co-edited the Handbook of Cross Cultural Management Research and the Handbook of Organizational Culture and Climate, both with Sage Press.

Jean-Luc Arregle is Professor of Strategy at EM Lyon Business School. His principal research interests are international modes of entry, regional strategies, multilevel methods, and family firms. He has published articles in such journals as Journal of International Business Studies, Strategic Management Journal, Academy of Management Journal, Journal of Management Studies and Management International Review.

Xavier Martin (PhD, Michigan) is Professor of Strategy, IB and Innovation at Tilburg University. His research examines how corporate strategies (including international expansion strategies), interfirm relationships, and knowledge-based assets affect each other and jointly affect firm performance. In adition to JIBS, he has published in Administrative Science Quarterly, Academy of Management Journal, Strategic Management Journal, Organization Science and Management Science among others. He has earned the Haynes Prize for Best Paper and Richard N. Farmer Best Dissertation Award from the Academy of International Business, and other research prizes including Best International Paper (now Dexter award) from the Academy of Management. 